\section{References}

BAIN, R. V. S. (1954) Studies on haemorrhagic septicaemia of cattle. I. Naturally acquired immunity in Siamese buffaloes. British Veterinary Journal 110, 481484

BAIN, R. V. S., DE ALWIS, M. C. L., CARTER, G. R. \& GUPTA, B. K. (1982) Haemorrhagic septicaemia. FAO Animal Health and Production Paper No 33. Rome, Food and Agriculture Organization of the United Nations. pp 11-33 BOKHOUT, B. A., VAN GAALEN, C. \& VAN DER HEYDEN, P. J. (1981) A selected water-in-oil emulsion: composition and usefulness as an immunological adjuvant. Veterinary Immunology and Immunopathology 2, 491-500

CARTER, G. R. (1955) Studies on Pasteurella multocida. I. A haemagglutination test for identification of serological types. American Journal of Veterinary Research 16, 481-484

CARTER, G. R. \& DE ALWIS, M. C. L. (1989) Pasteurella multocida. In Pasteurella and pasteurellosis. Eds C. Adlam, J. M. Rutter. London, Academic Press. pp 131-160

DE ALWIS, M.C. L. (1992) Haemorrhagic septicaemia: a general review. British Veterinary Journal 148, 99-112

HEDDLESTON, K. L., GALlaGHER, J. E. \& REBERS, P. A. (1972) Fowl cholera: gel diffusion precipitin test for serotyping Pasteurella multocida from avian species. Avian Diseases 16, 925-936

HIRAMUNE, T. \& DE ALWIS, M. C. L. (1982) Haemorrhagic septicaemia carrier status of cattle and buffaloes in Sri Lanka. Tropical Animal Health and Production 14, 91-92

JOHNSON, R. B., DAWKINS, H. J. S., SPENCER, T. L., SAHAREE, A. A., BAHAMAN, A., RAMDANI, R. \& PATTEN, B. E. (1989) Evaluation of bovine antibody responses to haemorrhagic septicaemia vaccine. Research in Veterinary Science 47, 277-279

JONES, T. \& HUASSAINI, S. (1982) Outbreak of Pasteurella multocida septi- caemia in fallow deer (Dama dama). Veterinary Record 110, 451-452

MUNIANDY, N., LOVE, D. M. \& MUKKUR, T. K. S. (1998) Immunogenicity of purified lipopolysacharide or protein-oligosacharide conjugates of Pasteurella multocida type 6:B in mice. Comparative Immunology and Microbiology of Infectious Diseases 21, 257-279

MUSTAFA, A. A., GHALIB, H. W. \& SHIGIDI, M. T. ( 1978) Carrier rate of Pasteurella multocida in cattle associated with an outbreak of haemorrhagic septicaemia. British Veterinary Journal 134, 375-378

MYINT, A. \& CARTER, G. (1989) Prevention of haemorrhagic septicaemia with a live vaccine. Veterinary Record 124, 508-509

MYINT, A. \& CARTER, G. (1990) Field use of haemorrhagic septicaemia live vaccine. Veterinary Record 126, 648-000

MYINT, A., CARTER, G. \& JONES, T. (1987) Prevention of experimental haemorrhagic septicaemia with a live vaccine. Veterinary Record 120, 500-502 NAGY, L. K. \& PENN, C. W. (1976) Protection of cattle against experimental haemorrhagic septicaemia by the capsular antigens of Pasteurella multocida, types B and E. Research in Veterinary Science 20, 249-253

OSE, E. E. \& MUENSTER, O. A. (1968) A method for evaluation of vaccines containing Pasteurella multocida. American Journal of Veterinary Research 29, 1863-1866

SHAH, N. H., SHAH, N. H. \& DE GRAAF, F. K. (1997) Protection against haemorrhagic septicaemia induced by vaccination of buffalo calves with an improved oil adjuvant vaccine. FEMS Microbiology Letters 155, 203-207

SINGH, N. (1948) Nasal carriers in bovine pasteurellosis. Indian Journal of Veterinary Science and Animal Husbandry 18, 261-278

VEKEN, J., SHAH, N. H., KLAASEN, P., OUDEGA, B. \& DE GRAAF, F. K. (1996) Binding of host iron-binding proteins and expression of ironregulated membrane proteins by different serotypes of Pasteurella multocida causing haemorrhagic septicaemia. Microbial Pathogenesis 21, 59-64

\title{
Intraocular pressure of juvenile loggerhead sea turtles (Caretta caretta) held in different positions
}

\author{
B. Chittick, C. HaRms
}

Veterinary Record (2001) $149,587-589$

\section{B. Chittick, DVM,}

Environmental Medicine Consortium and Department of Clinical Sciences, North Carolina State University College of Veterinary Medicine, 4700 Hillsborough Street, Raleigh, NC 27606, USA C. Harms, DVM, PhD, DACZM, Environmental Medicine Consortium and Department of Clinical Sciences, North Carolina State University College of Veterinary Medicine, Center for Marine Sciences and Technology, 303 College Circle, Morehead City, NC 28557, USA

\begin{abstract}
The intraocular pressure of 12 apparently healthy juvenile loggerhead sea turtles (Caretta caretta) was determined by applanation tonometry while the turtles were held in dorsoventral, ventrodorsal, and headdown suspended positions. The median intraocular pressures were $5 \mathrm{mmHg}$ (range 4 to $9 \mathrm{mmHg}$ ) in the dorsoventral position, $7 \mathrm{mmHg}$ (range 5 to $12 \mathrm{mmHg}$ ) in the ventrodorsal position, and $23 \mathrm{mmHg}$ (range 17 to $33 \mathrm{mmHg}$ ) in the suspended position.
\end{abstract}

TONOMETRY measures the intraocular pressure which results from the balance between the inflow and outflow of aqueous humour in the eye. The technique helps in the diagnosis of ocular pressure abnormalities, such as hypertension and glaucoma, which may severely or permanently impair vision, and ocular hypotension, which may indicate uveitis. Applanation tonometry measures the intraocular pressure indirectly by measuring the force required to flatten a constant area of the corneal surface (Strubbe and Gelatt 1999). The battery-operated Tono-pen $\mathrm{XL}$ applanation tonometer (Mentor Ophthalmics) incorporates a strain gauge transducer and microprocessor which determine electronically the pressure needed to indent a $1.2 \mathrm{~mm}$ diameter circle of cornea (Hessemer and others 1989, Strubbe and Gelatt 1999). Its portability and accuracy have contributed to its widespread clinical use in human and veterinary medicine (Hessemer and others 1989, Strubbe and Gelatt 1999). Reference ranges of intraocular pressures measured with the instrument are available for most domestic animal species (Miller and others 1990, 1991, Priehs and others 1990) but fewer data have been published for exotic or wild animal species, and fewer still for non-mammals; they are available, however, for raptors (Stiles and others 1994) and alligators (Whittaker and others 1995).

In this study, the intraocular pressure was determined in healthy juvenile loggerhead sea turtles (Caretta caretta) held in dorsoventral, ventrodorsal and head-down suspended positions, positions in which turtles are commonly restrained during medical and surgical procedures.

\section{MATERIALS AND METHODS}

Twelve wild juvenile loggerhead sea turtles were evaluated for a health survey involving laparoscopic sexing conducted by 
the National Marine Fisheries Service along the North Carolina coast in the summer of 2000 . The procedures were conducted under permit from the United States Fish and Wildlife Service (number TE-676379-2). The turtles were collected from fishermen's pound nets and transported by boat to shore for examination, blood collection and surgical sexing. Each turtle was treated with $25 \mathrm{mg} / \mathrm{kg}$ tetracycline (LA200; Pfizer) subcutaneously as a bone marker to determine its age if it was later stranded and the carcase recovered. The turtles were placed in ventrodorsal recumbency and strapped to padded wooden racks to restrain them during the surgical procedures. A small amount $(1 \mathrm{ml})$ of 2 per cent lidocaine hydrochloride (Phoenix Scientific) was administered subcutaneously in one inguinal region for local anaesthesia before each turtle was prepared for surgery. Fifteen minutes later the animals were suspended head-down by leaning the rack against a support at 70 to $80^{\circ}$ from the vertical for a period of 15 to 30 minutes while the turtles were sexed. The turtles were then positioned ventrodorsally for subcutaneous fat biopsies to be collected from the other inguinal region. They generally resisted handling but would become calm within 30 to 60 seconds after being placed in any particular position, and they generally reacted little, if at all, to the administration of lidocaine, and gave no response to either the laparoscopy or the fat biopsy. The turtles were allowed to recover in dorsoventral recumbency, and after the operation their buoyancy was assessed by their ability to dive in a 300 gallon circular tank. Provided they could submerge successfully, they were released back into the sea off the North Carolina coast.

In conjunction with this health survey, the intraocular pressures were measured in both eyes of each loggerhead while they were held in the dorsoventral, ventrodorsal and head-down suspended positions. The tonometry readings were collected between 11.00 and 17.00 . The eyes of the turtles were anaesthetised topically with one or two drops of 0.5 per cent proparacaine hydrochloride (Bausch \& Lomb Pharmaceuticals) before a Tono-pen XL tonometer (Mentor Ophthalmics) was applied to the centre of the cornea. The turtles generally remained calm and still for the measurements. The tonometer's transducer was covered with a new sterile latex membrane for each turtle. Each turtle was kept in each position for at least five minutes before the application of the tonometer. The measurements in the dorsoventral position were made before the turtles were strapped to boards and after they had recovered from the surgical procedures. The ventrodorsal measurements were made after the loggerheads had been strapped to the boards and before they were sexed. Immediately before the laparoscopic incision was made, readings were taken with the turtles in the head-down suspended position. Five measurements were obtained for each eye in each position and the average was recorded by one of the two authors. Any readings taken while an animal was blinking or retracting its globe were discarded.

Potential associations between the intraocular pressure and the right or left eye were evaluated for each body position by the Wilcoxon signed rank test, and associations between the pressure and the turtle's sex, or with the observer were determined by Wilcoxon rank sum tests (Hollander and Wolfe 1973). To incorporate all the data collected, the Kruskal-Wallis test followed by a Dunn's multiple comparison test was used to evaluate associations between the intraocular pressure and body position (Hollander and Wolfe 1973). A probability value less than 0.05 was considered significant.

\section{RESULTS}

All the loggerheads appeared to be in good body condition and health on the basis of clinical and haematological find-

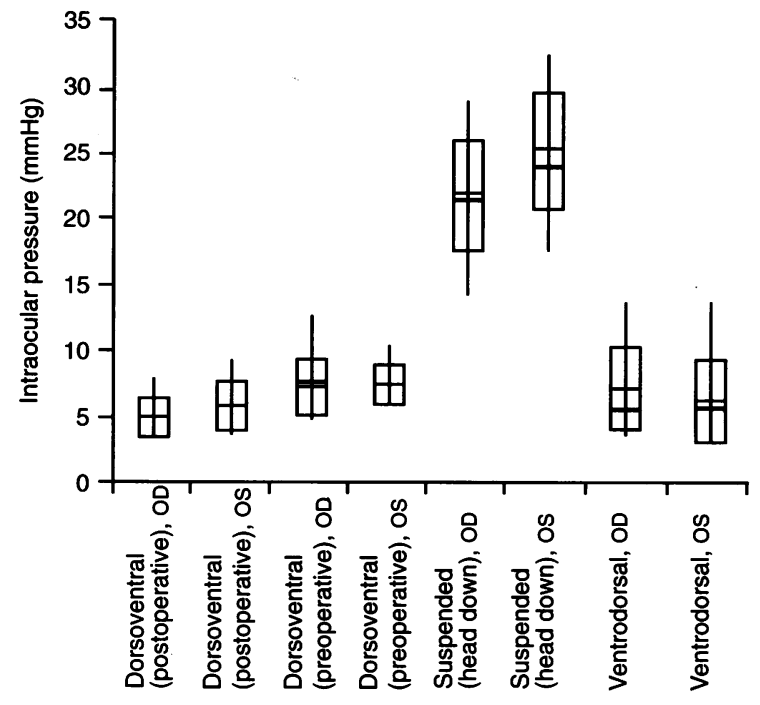

FIG 1: Intraocular pressures ( $\mathrm{mmHg}$ ) measured with a tonometer in 12 juvenile loggerhead sea turtles held in different body positions. The box represents 1 sd around the mean (solid horizontal line) and the whisker represents the range for the data. Where not identical with the mean, median values are represented by the thin double horizontal lines. OD Right eye, OS Left eye ings. Their weights ranged from 18.4 to $56.6 \mathrm{~kg}$, with a mean (sd) of $39.3(9.9) \mathrm{kg}$. There were five males and seven females.

The results of the measurements of intraocular pressure are shown in Fig 1. In the dorsoventral position the median pressure was $5 \mathrm{mmHg}$ (range 4 to $9 \mathrm{mmHg}$ ), in the ventrodorsal position it was $7 \mathrm{mmHg}$ (range 5 to $12 \mathrm{mmHg}$ ) and in the head-down suspended position it was $23 \mathrm{mmHg}$ (range 17 to $33 \mathrm{mmHg}$ ). In the head-down suspended position, four turtles developed oedema of the periocular tissue which obstructed access to the corneal surface and made it impossible to record accurate readings. There were no significant differences between the intraocular pressures recorded in the eyes of individual turtles. There were no statistically significant differences between the intraocular pressures recorded in turtles of either sex, and no significant differences between the results obtained by the two recorders. The intraocular pressure was significantly higher in the head-down suspended position than in the other two positions $(\mathrm{P}<0.0001)$. The intraocular pressures recorded in the ventrodorsal position were slightly higher than those recorded in the dorsoventral position but the differences were not significant.

\section{DISCUSSION}

The efforts to conserve sea turtles and the medical management of stranded and captive sea turtles have both increased in recent years. Diagnostic tools such as tonometry have the potential to improve the assessment and treatment of ocular conditions in sea turtles. This study provides baseline reference ranges for the intraocular pressures of wild-caught, juvenile loggerhead sea turtles.

In the dorsoventral and ventrodorsal positions, the turtles had considerably lower intraocular pressures than the published ranges for the tonometer in non-anaesthetised dogs, cats, horses and rats $(13[1.2] \mathrm{mmHg}$ ) (Cabrera and others 1999), great horned owls $(10.8[3.6] \mathrm{mmHg}$ ) (Stiles and others 1994), crocodilians more than $50 \mathrm{~cm}$ long $(11.6[0.5]$ $\mathrm{mmHg}$ ) (Whittaker and others 1995), but similar values to anaesthetised Thomson gazelles $(7 \cdot 6[1 \cdot 6] \mathrm{mmHg}$ ) (Ofri and others 2000). The lower pressures may be due to differences in the thickness, curvature or rigidity of the central cornea of the sea turtle eye. Anatomical differences in size, shape or rigidity of the cornea have been proposed to explain the lower intraocular pressure observed in nocturnal great horned owls as compared with diurnal raptors (Stiles and others 1994). 
In Thomson gazelles, anaesthesia, genetics, or increased ocular drainage were postulated to account for the low intraocular pressures observed (Ofri and others 2000).

The low intraocular pressures in the sea turtles may have contributed to the difficulty in collecting readings. The specific tonometer used, originally designed for human use, most accurately estimates pressures in the 11 to $20 \mathrm{mmHg}$ range, when compared with the Goldmann tonometer which is considered to be the gold standard in human beings (Frenkel and others 1988). In lower pressure ranges of 4 to $10 \mathrm{mmHg}$, the tonometer used has been found to overestimate the pressure slightly, while underestimating it slightly in ranges of 21 to 30 $\mathrm{mmHg}$ in human beings (Frenkel and others 1998). Similar trends have been reported in rabbits, although the agreement between the tonometer and an intraocular pressure transducer was concluded to be clinically acceptable for intraocular pressures between 3 and $30 \mathrm{mmHg}$ (Abrams and others 1996). In this study, several averaged readings of $4 \mathrm{mmHg}$ were recorded in the dorsoventral position, suggesting that apparently healthy sea turtles may have intraocular pressures at the lower acceptable limits of accuracy of the tonometer used.

Many factors affect intraocular pressure, including ocular disease, blood pressure, time of day (diurnal variation), activity level, circulating hormone levels, anaesthetics, and body position (Schottenstein 1996, Gum and others 1999). In human beings applanation tonometry has demonstrated that the intraocular pressure is significantly higher in supine than in sitting patients, probably as a result of the lower gravitational resistance of blood flow to the head in the supine position (Buchanan and Williams 1985). Intraocular pressures of up to three times normal occur when human patients are suspended head-down (Friberg and others 1987). Such increases have been associated with increases in episcleral venous pressure and are probably due to gravitational shifts in fluids or the orbit which increase vascular volume and lead to venous pressure gradients in the eyes and head (Friberg and others 1987, Linder and others 1988). The significant increases in intraocular pressure when the loggerheads were suspended head-down were probably due to similar mechanisms. Although the specific mechanism is uncertain, the increases in pressure clearly indicate that there are significant physiological changes with changes in posture.

Short-duration ocular hypertension associated with an abnormal body position is unlikely to result in permanent ocular damage. However, sustained or very large increases in intraocular pressure indicate potentially harmful ocular or systemic conditions that require veterinary attention. In this study, keeping the turtles in a head-down suspended position for 15 to 30 minutes did not result in corneal oedema, blindness, or any other obvious abnormalities, as might have been expected with acute pathological ocular changes associated with large increases in intraocular pressure. Furthermore, three of the turtles were recaptured feeding in pound nets within three months of the study and none showed any signs of ocular or general ill health. Consideration of body position and the duration of time in inverted positions, however, is warranted during restraint, medical or surgical procedures involving sea turtles.

\section{ACKNOWLEDGEMENTS}

The authors thank Joanne McNeill, Dr David Owens, the North Carolina State University College of Veterinary Medicine Ophthalmology Service, Sheryan Epperly, Ruth Boettcher, Dr Andrew Stamper, and the volunteers of the 2000 Sea Turtle Rodeo, for their support and contributions to this project. They also thank Dr Michael Davidson and Dr Michael Stoskopf for support and review of the manuscript.

\section{References}

ABRAMS, L. S., VITALE, S. \& JAMPEL, H. D. (1996) Comparison of three tonometers for measuring intraocular pressure in rabbits. Investigative Ophthalmology and Visual Science 37, 940-944

BUCHANAN, R. A. \& WILLIAMS, T. D. (1985) Intraocular pressure, ocular pulse pressure, and body position. American Journal of Optometry and Physiological Optics 62, 59-62

CABRERA, C. L, WAGNER, L. A., SCHORL, M. A., BOHR, D. F. \& COHAN, B. E. (1999) Intraocular pressure measurement in the conscious rat. Acta Ophthalmologica Scandinavica 77, 33-36

FRENKEL, R. E., HONG, Y. J. \& SHIN, D. H. (1988) Comparison of the Tonopen to the Goldmann applanation tonometer. Archives of Ophthalmology 106, 750-753

FRIBERG, T. R., SANBORN, G. \& WEINREB, R. M. (1987) Intraocular and episcleral venous pressure increase during inverted posture. American Journal of Ophthalmology 103, 523-526

GUM, G. G., GELATT, K. M. \& OFRI, R. (1999) Physiology of the eye. In Veterinary Ophthalmology. 3rd edn. Ed K. N. Gelatt. Philadelphia, Lea \& Febiger. pp 151-182

HESSEMER, V., ROSSLER, R. \& JACOBI, K. W. (1989) Tono-pen, a new tonometer. International Ophthalmology 13, 51-56

HOLLANDER, M. \& WOLFE, D. A. (1973) Nonparametric Statistical Methods. New York, John Wiley and Sons. pp 26-82

LINDER, B. J., TRICK, G. L. \& WOLF, M. L. (1988) Altering body position affects intraocular pressure and visual function. Investigative Ophthalmology and Visual Science 29, 1492-1497

MILLER, P. E., PICKETT, J. P. \& MAJORS, L. J. (1990) Evaluation of two applanation tonometers in horses. American Journal of Veterinary Research 51, 935 937

MILLER, P. E., PICKETT, J. P., MAJORS, L. J. \& KURZMAN, I. I). (1991) Evaluation of two applanation tonometers in cats. American Journal of Veterinary Research 52, 1917-1921

OFRI, R., HOROWITZ, I. H. \& KASS, P. H. (2000) How low can we get? Tonometry in the Thomson gazelle (Gazella thomsoni). Journal of Glaucoma 9, $187-189$

PRIEHS, D. R., GUM, G. G., WHITLEY, R. D. \& MOORE, L. E. (1990) Evaluation of three applanation tonometers in dogs. American Journal of Veterinary Research 51, 1547-1550

SCHOTTENSTEIN, E. M. (1996) Intraocular pressure and tonometry. In The Glaucomas. 2nd edn. Eds R. Ritch, M. B. Shields, T. Krupin. St Louis, MosbyYear Book. pp 407-428

STILES, J., BUYUKMIHCI, N. C. \& FARVER, T. B. (1994) Tonometry of normal eyes in raptors. American Journal of Veterinary Research 55, 477-479

STRUBBE, D. T. \& GELATT, K. N. (1999) Ophthalmic examination and diagnostic procedures. In Veterinary Ophthalmology. 3rd edn. Ed K. N. Gelatt. Philadelphia, Lea \& Febiger. pp 427-466

WHITTAKER, C. J., HEATON-JONES, T. G., KUBILIS, P. S., SMITH, P. J. BROOKS, D. E., KOSAREK, C., MACKAY, E. O. \& GELATT, K. N. (1995) Intraocular pressure variation associated with body length in young American alligators (Alligator mississippiensis). American Journal of Veterinary Research 56, 1380-1383

\section{$\square$ ABSTRACT}

\section{'Battered pets': sexual abuse}

AMONG 448 cases of non-accidental injuries to small animals reported by a random sample of practitioners 28 were sexual in nature; 21 dogs, five cats and two unspecified species were involved. The evidence was based on the types of injury, the behaviour of the owners, statements by witnesses, and confessions. There were penetrative vaginal and anorectal injuries, perianal damage and trauma to the genitals. Some of the injuries, such as castration, were extreme and some were fatal, but in some cases there was no obvious damage. The injuries were similar to those described in cases of child abuse and in human forensic pathology.

MUNRO, H. M. C. \& THRUSFIELD, M. V. (2001) 'Battered pets': sexual abuse. Journal of Small Animal Practice 42, 333-337 